\title{
Cytogenetic relationships between some species of Setaria L.(Poaceae)
}

\author{
Soliman A. Haroun \\ Department of Biological and Geological Sciences, \\ College of Education, Kafr El Sheikh, \\ Tanta University, Egypt.
}

Haroun, S. A. 2002. Cytogenetic relationships between some species of Setaria L.(Poaceae). Taeckholmia 22(1):5563.

Mitotic karyotype structure, meiotic behavior, pollen characteristics and seed setting of six species of genus Setaria were investigated in six species of Setaria L. Setaria verticillata, S. italica, S.viridis and S. glauca were found diploid $(2 \mathrm{n}=18)$ and $S$. sphacelata and $S$. plaicatilis are tetarploids $(2 \mathrm{n}=36)$. Karyotype measurements of the diploid species, to some extent, reflect their genetic stability except $S$. italica. This species has the longest chromosomes among the investigated species with degree of variation between chromosomes. A degree of variation was also observed in the karyotype of tetraploids. Irregular meiosis, chain trivalents and univalents were observed in $S$. italica and S. sphacelata. Other diploid species show regular meiosis. Tetraploids show various types of meiotic chromosome associations. Tetraploids also showed large pollen compared with diploids. Pollen fertility and seed setting of dipliod species are higher compared to that recorded for tetraploids.

Key words: Karyotype structure, Meiotic behaviour, Setaria.

\section{Introduction}

The genus Setaria L. belongs to Poaceae with more than 100 species distributed throughout tropical, subtropical and warm regions (Clayton \& Renvoize 1986). Many species of this genus are of economic importance (Wang et al 1995).

South West part of Saudi Arabia is rich with many species and genera of the grass family (Poaceae). Setaria is represented by six species mostly common in that region (Chaudahry 1989). Compared to other grasses, Setaria has been subjected to few recent studies (Haroun 1997, Chennaveeraiah et al 1991 Devos et al 2000; Le Thierry et al 1998, Wang et al 1995, Khan 1997 ), with no record of any studies on the area of South West of Saudi Arabia. However, this genus is still badly in need of modern revision for its cytogenetics. This investigation has been undertaken in order to gain insight into its cytogenetics and species relationships of six species in this part of the world.

Parameters investigated in the present study are mitotic karyotype structure, meiotic chromosome behavior, pollen characters and seed setting. This work is also part of a program aimed to study the cytogenetics of grass family.

\section{Materials and methods}

Plant material for morphological description were collected from natural habitats at Abha, South South West Saudi Arabia, and kept as herbarium specimens at the Department of Biological Sciences, College of Science, King Khalid University, Abha, Saudi Arabia. Check for names was based on Chaudahry (1989) and Migahid (1978).

For karyotype studies, excised root-tips of germinated seeds were pretreated in \% 0.25 colchicine for $3 \mathrm{~h}$, fixed in 1:3 v/v acetic alcohol for $24 \mathrm{~h}$, hydrolyzed in I N HCl at $60^{\circ} \mathrm{C}$ for 10 min., washed in distilled water and stained in Feulgen reagent for 3h. Three to five 
well-spread, fully contracted metaphase plates were used to construct karyograms. Cells were photographed at a magnification of $\mathrm{x}=1200$ using X30 Olympus photomicroscope. Karyotypes were compared using a karyotype similarity index (KSI) (Richards 1972, Booth \& Richards 1976). This is a numerical technique designed to estimate the degree of resemblance between two karyotypes of any chromosome numbers.

The score calculated as follow:

$\begin{array}{lllc}\text { Chromosome type } & 2 \mathrm{x} & 4 \mathrm{x} & \text { Score } \\ \text { A } & 2 & 2 & 1 \\ \text { B } & 2 & 4 & 2 \\ \text { C } & 4 & 8 & 4\end{array}$

The maximum score of identical karyotypes always equal the dipliod chromosome count. KSI of the studied species were compared and the comparisons are plotted on a kulcinski square, grouping similar ploidy levels together.

For meiosis and pollen characteristics, young buds were fixed in fresh fixative solution at early morning. Anthers were macerated and squashed in $2 \%$ acetocramine using iron mordant needle for good preparation. Dividing cells were examined at diaknesis and metaphase I stages for chromosme association and chiasma frequency.

Pollen stainability was assessed using 2\% acetocarmine. Unstained pollens were considered sterile. Diameters of about 50 pollen were measured using calibrated eye piece and calculated as mean value for each species.

Seed setting was estimated at natural open pollination condition by examining five panicle for each species. About 100 florets were examined for each panicle and seed setting was calculated as percentage.

\section{Results and discussion}

\section{A. Morphology}

\section{Setaria verticillata}

This species is tufted annual grass, about $40 \mathrm{~cm}$ tall. Leaf blade up to $20 \mathrm{~cm}$ long and 4-10 wide. Panicle more or less up to $10 \mathrm{~cm}$ long with spikelets of $1-2.5 \mathrm{~mm}$ long. Lower glume shorter than upper glume. This species is widely distributed in all regions especially in cultivated areas. The present collections were from Najran and Abha, South West Saudi Arabia. No morphological differences were recorded in samples from the two places. Compared to the same species investigated from Egypt (Haroun 1997), no significance differences are evident except for plant height and leaf blade length.

\section{Setaria italica}

Plants of this species are tall up to 1.5 meter, rhizomatous and perennial. Leaf blade up to $50 \mathrm{~cm}$ long and about $15 \mathrm{~mm}$ wide. Panicle more dense and up to $30 \mathrm{~cm}$ long. Spikelets about $2.5 \mathrm{~mm}$ long. Upper and lower glumes shorter than spikelet. The upper is longer than the lower. Lower lemma thin and sterile. The species is widely distributed in cultivated areas.

\section{Setaria viridis.}

Annual grass, up to $30 \mathrm{~cm}$ tall. Leaf blade about $15 \mathrm{~cm}$ long and about $12 \mathrm{~mm}$ wide. Panicle about $8 \mathrm{~cm}$ long with spikelets of $1.5 \mathrm{~mm}$. Lower glume about one third of the spikelet, the upper one as long as the spikelet. Lower glumes sterile and palea is as tall as the length of lower lemma. The species is common and widely distributed. 
Cytogenetic relationships between some species of Setaria L.(Poaceae).

\section{4-Setaria glauca (pumila)}

Tufted annual grass scattered in agricultural areas. Plants are 50-100 cm tall. Leaf blade of about $20 \mathrm{~cm}$ long and $7 \mathrm{~mm}$ wide. Panicle dense and cylindrical. Spikelets ovate, about 2-5 mm long, Glumes shorter than spikelet. Lower and upper lemma are staminate with palea almost the same length as the lemma.

\section{Setaria sphacelata}

Perennial grass with rhizomes. Culms about $1.5 \mathrm{~m}$ tall and glabrous. Leaf blade flat up to $40 \mathrm{~cm}$ long and 5-15 mm wide. Panicle dense and cylindrical, up to $50 \mathrm{~cm}$ long. Spikelets purple $2.5 \mathrm{~mm}$ long . Lower glume shorter than the upper one. Both are shorter than spikelet.

\section{Setaria plaicatilis}

Tufted perennial grass, up to $1 \mathrm{~m}$ tall. Leaf blade of about $30 \mathrm{~cm}$ long and $20 \mathrm{~mm}$ wide. Panicle $25 \mathrm{~cm}$ long. Spikelets about $2.5 \mathrm{~mm}$ long, lower glume up to the length of spikelet, upper glume is slightly taller than lower. Lower lemma as long as the spikelet. Upper lemma smooth and shiny

\section{B - Karyology}

The karyotype of the investigated species are presented in Fig. 1. Four are diploids with $2 \mathrm{n}=$ 18. This number is common to many genera and species of Poaceae (Haroun 1991, 1997, 2000, Devos et al 2000, Le Thierry 1998, Bala Sachdeva 1990). Except for Setaria italica, diploid species do not differ markedly in the mean chromosome length. This species has significantly longer chromosomes $(1.47 \mathrm{um}$ ) compared to other species (Fig.1-b). This result agrees with that previously recorded by Chandola (1959). The mean value of chromosome length rercorded for diploids being $1.18 \mathrm{um}$ against $1.29 \mathrm{um}$ for tetraploids (Table 4). This finding is in contrast to that previously recorded by Haroun et al ( 1992) for the same ploidy levels for species of the genus Panicum (Poaceae).

The karyotype measurements recorded for $S$. verticillata are significantly high compared with that previously recorded for the same species from Egypt (Haroun, 1997). No satillited chromosomes or secondary constrictions are observed in the chromosome set (Fig. 1.a). Karyotype morphology and measurements of this species also differ significantly from that recorded for S. italica. This result indicates that the two species are cytogenetically different as previously stated by Poirier and Pernes (1986). Based on life form, perennial species of Setaria tend to have slightly longer chromosomes than annuals, in the present study three of the four diploids are annuals and the two tetraploids are perennials.

With regard to centromere position as assessed by arm ratio, all species have metacentric, submetacentric and telocentric types of chromosomes (see Table 1; Fig. 1). Variation in chromosome length within the karyotype set of S. italica and the high values of standard errors recorded for this parameter, and also for arm ratio reflect, to great extent, the heterogeneity of karyotype structure of the species. This is in agreement with Devos et al (1998), who observed some sort of rearrangement in the genome structure of this species. This rearrangements is probably due to wide distribution of the species in cultivated areas where possibilities of partial crosses with unknown compatible grasses is available and even highly expected. 
a

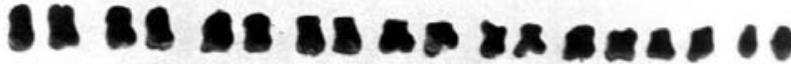

b

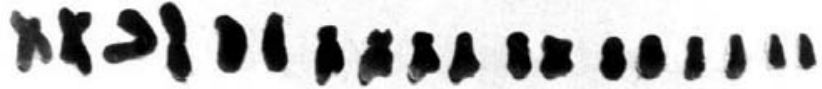

C

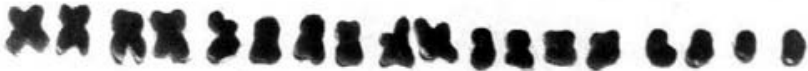

d

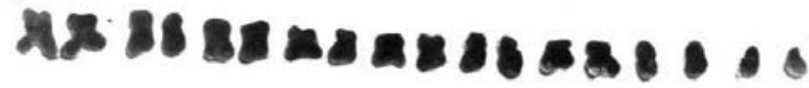

e

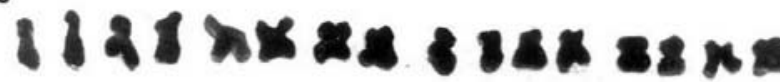

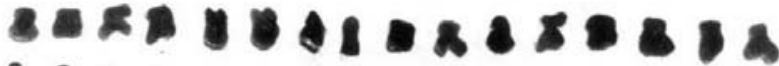

$\bullet \bullet$

f

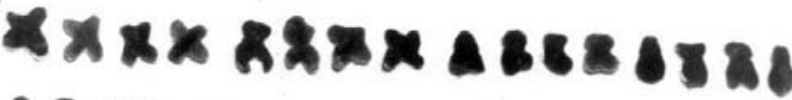
$0000 \times 0 \times 2 \times 2000$ $\bullet \bullet \bullet$

Fig. 1(a-f): Karyotypes of six species of Setaria. a, S. verticillata ; b, S.italica; c, S. viridis ; d, S. glauca; e, S. sphacelata; f, S. plaicatilis

Table 1: Chromosome number, mean chromosome length, mean arm ratio and karyotype formula of the Setaria species examined.

\begin{tabular}{|l|l|l|l|l|l|}
\hline \multicolumn{1}{|c|}{ Species } & Life form & 2n & $\begin{array}{l}\text { Chromosome } \\
\text { Length } \pm \text { S.E }\end{array}$ & $\begin{array}{c}\text { Arm Ratio } \\
\pm \text { S.E. }\end{array}$ & \multicolumn{1}{|c|}{ Karyotype Formula } \\
\hline Setaria verticillata & Annual & 18 & $0.99 \pm 0.07$ & $1.27 \pm 0.07$ & $12 \mathrm{~m}+4 \mathrm{sm}+2 \mathrm{t}$ \\
\hline Setaria italica & Perennial & 18 & $1.47 \pm 0.11$ & $1.34 \pm 0.18$ & $10 \mathrm{~m}+6 \mathrm{sm}+2 \mathrm{t}$ \\
\hline Setaria viridis & Annual & 18 & $1.31 \pm 0.08$ & $1.30 \pm 0.80$ & $14 \mathrm{~m}+2 \mathrm{sm}+2 \mathrm{t}$ \\
\hline Setaria glauca & Annual & 18 & $1.15 \pm 0.09$ & $1.24 \pm 0.09$ & $12 \mathrm{~m}+4 \mathrm{sm}+2 \mathrm{t}$ \\
\hline Setraia sphacelata & Perennial & 36 & $1.21 \pm 0.13$ & $1.11 \pm 0.12$ & $22 \mathrm{~m}+10 \mathrm{sm}+4 \mathrm{t}$ \\
\hline Setria plaicatilis & Perennial & 36 & $1.37 \pm 0.09$ & $1.19 \pm 0.15$ & $28 \mathrm{~m}+4 \mathrm{sm}+4 \mathrm{t}$ \\
\hline
\end{tabular}


Cytogenetic relationships between some species of Setaria L.(Poaceae).

Table 2: Karyotype similarity matrix coefficient for the six studied species of Setaria.

\begin{tabular}{|l|l|l|l|l|l|l|}
\hline S. verticillata & 100 & & & & & \\
\hline S. italica & 23 & 100 & & & & \\
\hline S. viridis & 56 & 67 & 100 & & & \\
\hline S. glauca & 67 & 39 & 67 & 100 & & \\
\hline S. sphacelata & 34 & 39 & 50 & 39 & 100 & \\
\hline S. plaicatilis & 39 & 45 & 39 & 45 & 39 & 100 \\
\hline Species & S. vert. & S. ital. & S. viri. & S. gla. & S. sph. & S. plaic. \\
\hline
\end{tabular}

Based on karyotype structure and measurements it is of interest to note that the two species S. italica and S. viridis are highly similar (Fig.1- b \& c respectively). This points to a close genetic relationship between the two species as previously recorded by Wang et al (1995) who found no isozymatic differences between them. Li et al (1948) in fact had earlier concluded that $S$. viridis is the probable mediate progenitor of the cultivated $S$. italica. The karyotype morphology (Fig.1-d) and measurements of S. qlauca reflect its genetic stability as suggested for most diploids.

Regarding tetraploids, karyotype morphology (Fig. 1- e \& f), measurements and standard error values (Table 1) indicate high degree of variation between chromosomes in the set of $S$. sphacelata but not in that of $S$. plaicatilis. This, to great extent, reflects the heterogeneity of its genome. In this species, a degree of reorganization between chromosomes in the complement, accompanied with asymmetrical arm ratios has probably occurred. Based on these findings, it is predicted that this species is allotetraploid and a possibility of incorporation of two different diploid genomes in its structure is highly expected.

Different types of chromosomes were identified in the species investigated. The length ranged from 0.8 to $2.4 \mathrm{um}$ and the centromere positions varied from median to telocentric. Satellites or accessory (B) chromosomes were not identified (Fig.1).

Comparison of the karyotype of the species species by means of karyotype similarity index (KSI) and karyological relationships are displayed in table 2. The lowest degree of similarity (23\%) is recorded between S. italica and S. verticillata. The former also shows low similarity with all species except $S$. viridis (67\%), which support the close genetic relationship between the two species (Wang et al 1995). The same value of similarity was also recorded between the two annual species $S$. verticllata and $S$. glauca. The two tetraploids recorded a similarity of 39\%, which reflect their different origin and distinct karyotype structure.

Based on life form and habit the lowest degree of similarity recorded (23\%) was between an annual and a perennial species. This to some extent suggests that this character is cytogenetically controlled. The highest value is recorded between dipliods and tetraploids was $50 \%$ and is recorded for $S$. viridis and S. sphacelata. As the latter shows karyologically derived origin, it could be said that one of diploids (probably S. viridis ) participated in the parental genome of this species.

\section{Male meiosis and pollen characteristics.}

Among diploids, S. italica recorded the highest value of univalents. Chain bivalents and multivalents were also observed (Fig. 2-a ). As a consequence of this behavior low chiasma frequency is expected. This finding supports the suggestion of Devos et al (1998) that rearrangements in genome structure of this species has occurred. Meiosis of other diploids is almost regular with a low frequency of univalents(Fig. 2-b, c, d). Bivalents ratio varied from 


\section{S. A. Haroun}

species to another (Table 3) and seems likely to affect chiasma frequency. Diploid species recorded a mean ratio of 1.05 against 1.21 for tetraploids. This result is in contrast to that previously recorded by Haroun et al (1992) for some species of Panicum (Poaceae).

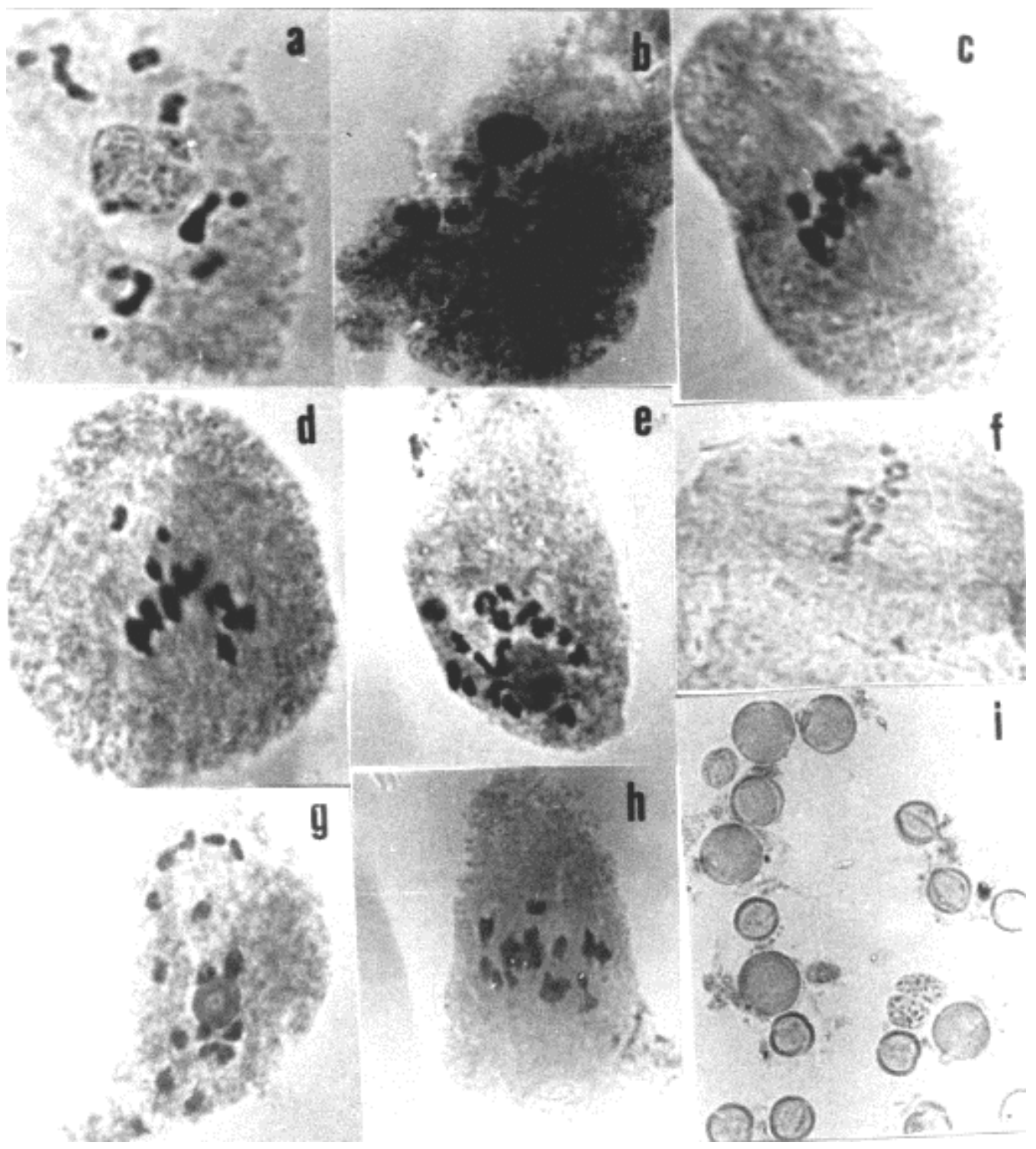

Figure 2(a-i): a, Diaknesis of S. itlica showing univalents and rod multivalents, b, diaknesis of $S$. verticillata; c, metaphase I of S. viridis; d, daknesis of $S$. glauca; e, diaknesis of $S$. sphacelata showing trivalents and rod bivalents; f, metaphase I of S.sphacelata with lagging chromosomes ; g,h, diaknesis and metaphase I of S. placiatilis; I, pollen grains of S. sphacelata with different size and sterile pollen. 
Cytogenetic relationships between some species of Setaria L.(Poaceae).

Table 3. Number of pollen mother cells (PMC,s) observed, chromosome association and chiasma frequency per bivalent for six species of Setaria.

\begin{tabular}{|c|c|c|c|c|c|c|}
\hline Species & No PMC’s & \multicolumn{4}{|c|}{ Linrom. Associatio $\quad n$} & Chias . freq . \pm S.E \\
\hline S. verticillata & 33 & 1.4 & 8.30 & 0.0 & 0.0 & $1.07 \pm 0.03$ \\
\hline S. italica & 41 & 1.9 & 6.80 & 0.8 & 0.0 & $1.04 \pm 0.05$ \\
\hline S. viridis & 25 & 1.7 & 8.15 & 0.0 & 0.0 & $1.71 \pm 0.03$ \\
\hline S. glauca & 16 & 1.2 & 8.40 & 0.0 & 0.0 & $1.01 \pm 0.07$ \\
\hline S. sphacelata & 27 & 1.9 & 8.20 & 3.5 & 1.8 & $1.16 \pm 0.09$ \\
\hline S. plaicatilis & 40 & 1.7 & 8.95 & 1.6 & 2.9 & $1.26 \pm 0.09$ \\
\hline
\end{tabular}

Table 4. Percentage of abnormal PMC's, pollen fertility, seed set and pollen diameter of six species of Setaria.

\begin{tabular}{|l|l|c|cc|c|}
\hline \multicolumn{1}{|c|}{ Species } & \%Abn. & \% Pollen fertility & \multicolumn{2}{c|}{ Pollen diameter } & \% Seed set \\
\cline { 4 - 6 } & PMC’S & \pm S.E & Range & mean \pm S.E. & S.E. \\
\hline S. verticillata & 5.1 & $91.6 \pm 1.34$ & $25-29$ & $25.7 \pm 1.21$ & $89.7 \pm 1.87$ \\
\hline S. italica & 7.6 & $89.9 \pm 1.42$ & $22-35$ & $31.1 \pm 2.11$ & $92.4 \pm 2.12$ \\
\hline S. viridis & 4.5 & $96.2 \pm 1.93$ & $20-27$ & $25.3 \pm 1.76$ & $75.2 \pm 2.34$ \\
\hline S. glauca & 6.5 & $77.8 \pm 1.82$ & $22-28$ & $27.2 \pm 2.01$ & $83.6 \pm 1.44$ \\
\hline S. spacelata & 7.1 & $71.8 \pm 2.10$ & $29-41$ & $35.6 \pm 1.65$ & $70.1 \pm 1.72$ \\
\hline S. plaicatilis & 5.2 & $87.3 \pm 2.34$ & $33-42$ & $37.2 \pm 1.34$ & $79.2 \pm 1.89$ \\
\hline
\end{tabular}

Not surprisingly, S. italica recorded low chiasma frequency inspite of its relatively longer chromosomes because abnormal meiosis was observed. On the other hand S. viridis recorded the highest value of chiasma among diploids as it has normal meiosis and long chromosomes compared to other two diploids (S. verticillata and S. glauca). Except S.italica it could be said that meiosis of diploids is regular. The value of chiasma frequency recorded for S. verticillata is significantly high compared to that previously recorded for the same species from Egypt (Haroun, 1997). However, this indicates the genetic stability of the species and could be regarded as evolutionary response to the challenge of normal pairing as previously suggested by Chandola (1959).

For the two tetraploids observation of multivalents is expected and associations in the form of trivalents and tetravalents were observed. To some extent $S$. plaicatilis shows higher ratio of bivalents and quadrivalents (Fig. 2-g \& h) compared to S. sphacelata. On the other hand, high level of trivalents and rod bivalents (Fig.2- e) recorded for S. sphacelata reflect its genetic instability and alloploid nature as previously stated by Poirier and Pernes (1986).

Based on meiotic configurations the treatment of the two tetraploid species as autotetraploid or allotetraploid is not justified. The two species represent an intermediate situation for the two types with high frequency of bivalents and some univalents, multivalents and quadrivalents. Such intermediates suggest that the two tetraploids are segmental allopolyploid as previously stated by Stebbins (1950), where the two genomes are rather alike or unlike but rather in between. The assumption that the two species are segmental allopolyploids is further supported by pollen fertility and seed set.

Some irregularites were observed including lagging and unoriented univalents (Fig.2f). Diploids recorded 5.92 mean value of these forms against 6.15 for tetraploids (Table 5). It 
seems likely that such irregularities affect normal pairing and cause a decrease in the ratio of chiasma frequency.

A positive relationship is clear between the percentage of seed setting and pollen fertility (Table 4). Diploid species, to some extent, show high pollen fertility compared to tetraploids (88.9\% vs $79.6 \%$ ). The lowest proportion of pollen fertility (71.8\%) is recorded in S. spacelata. The sterile pollen were always seen as small and unstained (Fig. 2-i).The mean values for meiotic parameters recorded for diploids and tetraploids show that the former have higher pollen fertility and seed set than the latter (Table 5).

Table 5. Mean values for chromosome length, arm ratio, chiasma frequency, abnormal PMC's, pollen fertility, pollen diameter and percentage of seed setting in diploids and tetraploids species of Setaria.

\begin{tabular}{|c|c|c|c|c|c|c|c|}
\hline $\begin{array}{c}\text { Ploidy } \\
\text { level }\end{array}$ & Chr.L. & A.R. & $\begin{array}{c}\text { Chias. } \\
\text { Freq. }\end{array}$ & $\begin{array}{c}\text { \% Ab. } \\
\text { PMC's }\end{array}$ & \%Fert. & $\begin{array}{c}\text { Poll. } \\
\text { Diam. }\end{array}$ & \% seed set \\
\hline 2n & 1.17 & 1.28 & 1.13 & 5.92 & 88.9 & 27.3 & 85.2 \\
$4 \mathrm{n}$ & 1.29 & 1.15 & 1.21 & 6.15 & 79.6 & 36.4 & 74.7 \\
\hline
\end{tabular}

Not surprisengly tetraploids have larger pollen than diploids (36.4 vs $27.3 \mu \mathrm{m}$ ). Pollen diameters of diploids ranged between 25.3-31.1 $\mu \mathrm{m}$ against 35.6-37.2 $\mu \mathrm{m}$ for tetraploids. Based on pollen measurements it seems likely that the ratio between diploids and tetraploids (1: 1.3) does not follow the ploidy level. Although there is no overlap in pollen diameter between diploids and tetraploids, this parameter could not accurately predict the ploidy level.

\section{References}

Bala, S. \& Sachdeva, S. K. 1990. Cytological and biochemical study of co-occuring diploid, tetraploid and hexaploid individuals of Setaria verticillata L. (poaceae). Phytologia. 68: 276-292 .

Booth, T.A. \& Richarads, A.T. 1976. Studies in the Hordeum murinum aggreate . I . Morphology . Bot . J . linn. Soc. 72:149-159.

Chandola, R.P. 1959. Cytogenetics of Millets. Cytologia 24:115-137.

Chaudhary, S.A. 1989. Grasses of Saudi Arabia, Saudi Ntional Herbarium, Ministry of Agriculture and Water, Kingdom of Saudi Arabia.

Chennaveeraiah, M. S, Hirvemath, S.C., Gupta, P.K. \& Tsuchiya, 1991. Cytogenetics of minor millets. Chromosome engineering in plants: (Elsevier Science Publishers: Amsterdam 37 : 613-627.

Clayton. W.D. \& Renvoize, S.A. 1986. Genea graminum : Grasses of the world . HMSO London.

Devos, K.M., Wang, Z.M., Bealse, J., Sasaki, T. \& Gale, M.D. 1998. Comparative genetic maps of for tail millet (Setaria italica) and rice (Oryza sativa). Theor-Appl-Genet. I 96: 63-68.

--------, Pittaway, T.S., Reynolds, A. \& Gale, M.D. 2000. Comparative mapping reveals a complex relationship between the pearl millet genome and those of foxtail millet and rice. Theor-appl-genet. Berlin; Springer-Verlag. 100(2):190-198.

Haroun, S.A. 1991. Cytogenetic investigations on some species of the genus Panicum L. ph.D. Thesis Tanta University, Egypt . 
Cytogenetic relationships between some species of Setaria L.(Poaceae).

Haroun, S.A., Richards, A.J. and Macleod, R. D. (1992) Genetic relationships between some millets (Panicum). The linn. Soc. of London 13:264-282 .

1997. Cytogenetic study on Setaria verticillata and Eragrostis egyptiaca from Egypt. Cytologia, 62(2):153-159 .

2000. Altitidnal effects, on cytogenetic and breeding of Panicum turgidum forrsk. Cytologia . 65:225-230 .

Khan, M.F. 1997. Cytological characteristation of Setaria pallidefusca (Schumach.) Stapf. and Hubb of District Rawalakot, Azad Kashmir-Pakistan. Cytologia 62(3):225-229 .

Le-Thierry-d’Ennequin, M., Panand, O; Brown, S., Siliak-Yakovlev, S.\& Sarr, - A . 1998. First evaluation of nuclear DNA content in Setaria genus by flow cytometry. J. hered Cary, NC: Oxford University press. Nov, dec. 89(6):556-558 .

Li, H.W., C. H., \& Apo, W.K. 1945. Cytological and genetical studies of the interspecific cross of the cultivated foxtail millet Setaria italica L. beauv., and the green foxtail millet, S. virids L. J. Am. Soc. Agron. washington, D.C. The society 37(1):32-54 .

Migahid, A.M. 1978. Flora of Saudi Arabia Vol. 2, king Saudi Univ. Press. Riyadh.

Poirier-Hamon, S. \& Pernes, T. 1986. Chromosome instability in somatic tissues of off springs from an interspecific hybrid between Setaria verticillata and Setaria italica. Acad. Sci. Paris: 302:319-322.

Richards, A.J. 1972. The karyology of some Taraxacum species from alpine regions in Europe. Bot. J. Linn. Soc., 65: 47-54.

Stebbins, G. L. 1950. Variation and evolution in plants. Columbia Univ. Press

Wang, R.L., Wendel, J.F.\& Dekrev, J. H. 1995. Weedy adaptation in Setaria spp. 11. Genetic diversity and population genetic structure in Setaria glauca, S. geniculata and $S$. faberii (Poaceae). Amer. J. Bot. 82:1031-1039 . 